\title{
Neurosurgeons and their contributions to modern-day athletics: Richard C. Schneider Memorial Lecture
}

\author{
Ian F. Dunn, M.D., Gavin Dunn, M.D., Ph.D., and Arthur L. Day, M.D. \\ Department of Neurosurgery, Brigham and Women's Hospital, Harvard Medical School, \\ Boston, Massachusetts
}

\begin{abstract}
$\checkmark$ Neurosurgeons in the last half-century have had considerable influence on modern-day athletics. In this article, the authors address the contributions made by neurosurgeons as clinician-scientists, particularly as these relate to the understanding and reduction of the incidence and severity of injury to the nervous system during athletic competition. American football has been a proving ground for the ability of the craniospinal axis to withstand and, in unfortunate cases, succumb to tremendous impact forces; in this way, it has served as a model for translational research and was the arena in which Dr. Richard Schneider made his greatest contributions to sports neurosurgery. Therefore, in his memory and in the spirit of the Schneider lectureship, the authors outline the notable contribution to modern-day athletics made by neurosurgeons as it applies to American football. Neurosurgeons have had considerable influence on reducing injury severity, and this cause has been championed by a few notable individuals whose efforts are discussed herein.
\end{abstract}

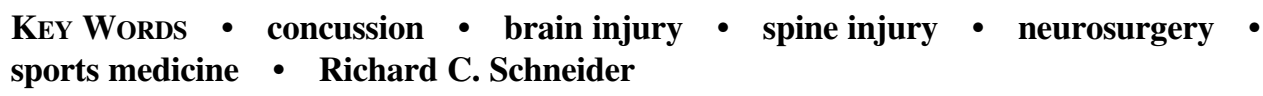

$\mathrm{N}$ EUROSURGEONS and their contributions to modernday athletics can be examined from the viewpoint of their individual athletic accomplishments while at school or from their role as treating physicians caring for individual athletes or teams. In this article, however, we address the contributions made by neurosurgeons as clinician-scientists who aimed at understanding and reducing the incidence and severity of injury to the nervous system during athletic competition. American football is an ideal model for translational research in the head (brain) and spine (spinal cord, nerve roots), and because it was the vehicle that Dr. Schneider used in his investigations, we have chosen it as our athletic vehicle to outline these contributions (Table 1).

\section{History of American Football}

American football began as a collegiate sport; the first "official" game was played between Princeton and Rutgers in 1869. According to observers, the game was "replete with surprise, strategy, prodigies of determination, and physical prowess." With the sport rapidly gaining in popularity, Harvard, Yale, Princeton, and Columbia formed the Intercollegiate Football Association in 1876. During a game in 1892, in which the Allegheny Athletic Association football team defeated the Pittsburgh Athletic Club,

Abbreviations used in this paper: AANS = American Association of Neurological Surgeons; CNS = Congress of Neurological Surgeons; JAMA = Journal of the American Medical Association; NCAA = National Collegiate Athletic Association; NFL = National Football League.
William "Pudge" Heffelfinger was reportedly paid \$500 to play, marking this contest as the first recorded "professional" football game. ${ }^{4}$

The sport prospered and increased in complexity. By 1906, exactly 100 years ago, interlocking formations, flying wedges, and "gang tackling" were commonplace tactics, and serious injury rates began to soar. In that year alone, there were 18 deaths attributable to football-related head or spinal injuries. ${ }^{4}$ These startling numbers prompted President Theodore Roosevelt, himself an avid fan, to threaten to make playing football a federal offense if the game was not made safer. In response, the Intercollegiate Athletic Association of the United States and the Intercollegiate Rules Committee were convened to make the game safer. These groups were merged 4 years later under the umbrella of the NCAA, which remains the oversight body to this day. That same year, the forward pass was adopted, and the game's complexity, popularity, and numbers of participants grew at a spectacular rate, ultimately replacing baseball in many people's opinion as the favorite American sport. As football grew, teams organized their personnel to include not only the players and coaches, but also a "bench" of medical staff that usually included a trainer, team physician (an internist or general practitioner), and an orthopedic surgeon.

During the first half of the last century, data about head and spine injuries were sparse. After World War II, the National Football Head and Neck Injury Register and the National Center for Catastrophic Sport Injury Research were created to monitor the incidence and severity of these types of injuries. In the years between 1945 and 1999, more than 700 fatalities were documented, includ- 
TABLE 1

Notable events in football and neurosurgeons' contributions*

\begin{tabular}{|c|c|}
\hline Date & Events \& Contributions \\
\hline 1869 & first American football game between Princeton \& Rutgers \\
\hline 1876 & Intercollegiate Football Association formed \\
\hline 1892 & first professional football game \\
\hline 1906 & 18 deaths; Teddy Roosevelt intervenes \\
\hline 1906 & IAAUS/IRC begin outlining safety measures \\
\hline $1950 \mathrm{~s}$ & $\begin{array}{l}\text { Richard Schneider defines anterior \& central cord syndromes \& } \\
\text { teardrop fracture }\end{array}$ \\
\hline 1961 & $\begin{array}{l}\text { Schneider formally establishes the neurosurgeon as part of athletic } \\
\text { enterprise in seminal report on football fatalities (JAMA) }\end{array}$ \\
\hline 1970s & $\begin{array}{l}\text { improved helmet standards \& outlawing of spear tackling lead } \\
\text { to reduction in severe brain injuries }\end{array}$ \\
\hline 1986 & Robert Cantu formalizes concussion grading \\
\hline $1990 \mathrm{~s}$ & $\begin{array}{l}\text { Joseph Maroon \& ImPACT objectify neuropsychological } \\
\text { sequelae from concussion }\end{array}$ \\
\hline 2002 & $\begin{array}{l}\text { ephedrine banned as a result of study by Julian Bailes, et al., } \\
\text { investigating causes of heatstroke deaths in young athletes }\end{array}$ \\
\hline 2006 & $\begin{array}{l}\text { Joseph Maroon, as team neurosurgeon for the Pittsburgh } \\
\text { Steelers, lifts the Vince Lombardi Trophy }\end{array}$ \\
\hline
\end{tabular}

* IAAUS/IRC = Intercollegiate Athletic Association of the United States/ Intercollegiate Rules Committee.

ing more than 600 deaths from nervous system injuries (497 brain and 116 spinal cord). ${ }^{7}$ Nonetheless, the players got bigger, the game got faster, and the hitting became fiercer. The player mentality and attitudes were to invoke physical dominance and intimidation toward the opponent, as exemplified by the following quotations:

If my mother put on a helmet and shoulder pads and a uniform that wasn't the same as the one I was wearing, I'd run over her if she was in my way. And I love my mother. ${ }^{9}$ -Bo Jackson

I wouldn't ever set out to hurt anyone deliberately unless it was, you know, important-like a league game or something. ${ }^{5}$ -Dick Butkus

\section{Richard C. Schneider}

Richard C. Schneider was born on May 29, 1913, in Newark, New Jersey. ${ }^{11} \mathrm{He}$ attended Dartmouth College, where he participated in collegiate swimming and lacrosse, and obtained his medical degree from the University of Pennsylvania. Shortly thereafter, with World War II ongoing, he joined the armed forces and served in the 36th General Hospital Unit in North Africa and Europe. The experience inspired him to pursue neurosurgery, and after returning from the war, he entered neurosurgery residency at the University of Michigan, a program headed at that time by Max Peet. Following a brief stint in practice in Cleveland, he returned to Michigan, where he remained for the rest of his career. He served as the department's chairman from 1969 to 1979 . He also served as the president of the AANS from 1974 to 1975, and was the Honored Guest of the CNS in 1977.

During his career, he made multiple major clinical contributions, particularly in describing the clinical features of cervical spine and spinal cord injuries. The central theme of his publications, the neuroanatomical basis of neurosurgical pathophysiology and injury, is exemplified in the classic neurosurgical textbook Correlative Neurosurgery, which he wrote with his Michigan colleagues Drs. Kahn, Bassett, and Crosby.$^{10} \mathrm{He}$ first described the anteri- or cord syndrome in 1951. In a 1954 summary of 15 cases (six from the literature, nine from a personal series), Schneider, et al., ${ }^{18}$ clarified the central cord syndrome. This is often caused by hyperextension injuries with cord impingement by ligamentum flavum or osteophytic spurs, and there is disproportionately greater weakness in the upper than in the lower extremities, with variable sensory changes (Fig. 1). He also described the teardrop fracture and the second-impact syndrome.

As an athlete and avid Michigan fan, Schneider maintained an intense enthusiasm for collegiate athletics, especially Michigan football. In the late 1950s and early 1960s, he became particularly interested in the head and spine injuries that occurred in sport. In a survey of 208 fatalities directly attributed to football (1947-1959), he noted a trend toward an increase in deaths from head and spinal cord injuries. In a classic report published in JAMA in 1961, Schneider and colleagues ${ }^{19}$ analyzed the mechanisms surrounding 14 neurosurgical football fatalities and on the basis of clinical and postmortem examinations, they carefully detailed the pathophysiological features of three of these cases. That report marked the beginning of the involvement of neurosurgeons and their observations in athletics as investigators whose aim was to reduce the incidence and severity of injury to the central and peripheral nervous systems, as illustrated in a quotation from the aforementioned article: "It is therefore important that these fatal injury statistics be evaluated from a neurosurgical standpoint." These authors also asserted that conclusions should be "founded on clinical and postmortem examinations, neuroanatomical studies of the mechanisms of injury, and their prevention by changes in equipment." 19

The first football helmet was used in 1893 in the ArmyNavy game. ${ }^{12}$ It was made predominantly of leather, and afforded little protection to the intracranial contents. By

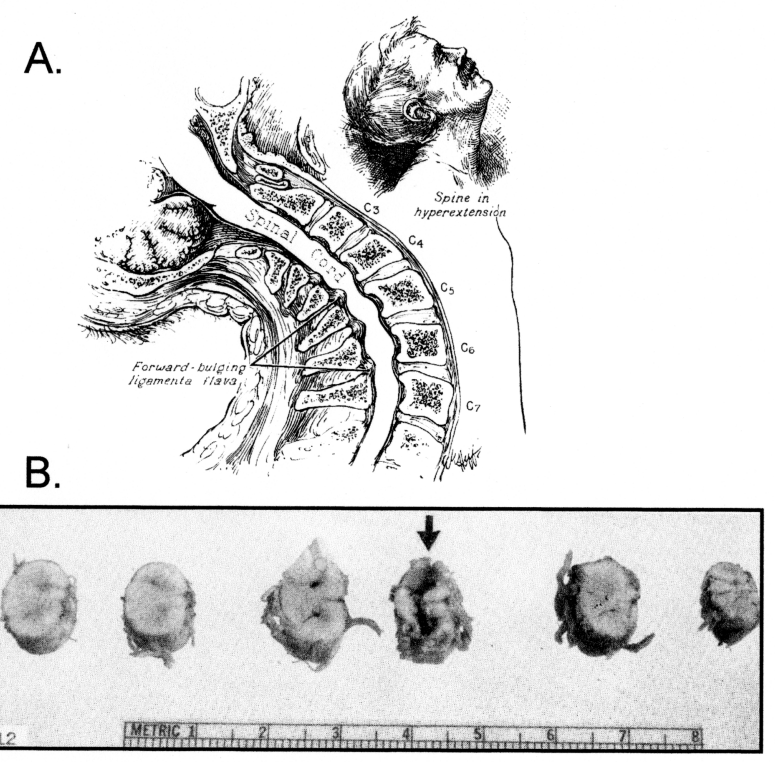

FIG. 1. A: Schematic descriptions of the central cord syndrome demonstrating the mechanism of injury. B: Photograph of an autopsy specimen showing the pathology of central cord syndrome. Reprinted with permission from The Journal of Neurosurgery $(11: 546-577,1954) .^{18}$ 
1940, helmets were required equipment by both the NCAA and the NFL. Nonetheless, there was a continued increase in catastrophic head injuries in the decades leading up to the 1970s. Schneider's position was that football helmets should be constructed on the basis of an anatomical knowledge of the skull and brain, coupled with an understanding of the mechanical principles of head injury. In the 1961 JAMA article ${ }^{19}$ he and his colleagues outlined recommendations to update football helmets: use material to decelerate linear forces, place face gear closer to the face, use chin straps, and pad the raised posterior aspect to avoid knifelike blows to the cervical spine.

Schneider established a laboratory model at the University of Michigan to study head and neck injuries, and these experiments ultimately led to the development of the protective helmets used today (Fig. 2). In addition, he used game and practice films to study the mechanisms causing these injuries, and his findings led to major rules changes banning so-called spearing and butt-blocking. The result was a dramatic reduction in the incidence of athletics-related "serious" head and spinal cord injury, as documented in the National Football Head and Neck Injury Register and the National Center for Catastrophic Sport Injury Research data statistics (Fig. 3). ${ }^{7,8}$

Although the benefits of the reduction of major catastrophic injuries were obvious, the extent and ultimate consequences of concussions remained poorly understood and were largely ignored until the 1980s. "Dingers" or concussions were commonplace and assumed to be benign. Because of the gladiator mentality of the sport, athletes were encouraged and expected to return to play as soon as possible, ignoring any lingering effects of these "minor" head injuries.

Modern data on the incidence and outcomes of these injuries, however, are quite startling. Well over $90 \%$ of all athletics-related head injuries are concussions, and up to

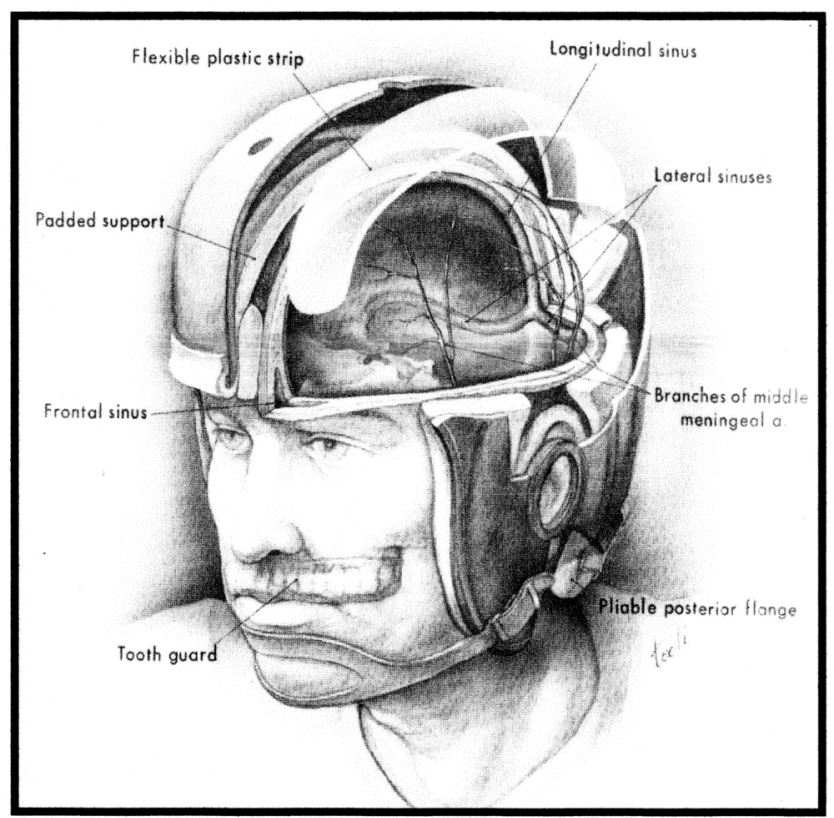

FIG. 2. Schematic design of football helmet as envisioned by Dr. Schneider. a. = artery. one in five high school and collegiate football players suffer a concussion each year. ${ }^{15,16}$ The relationship of socalled second-impact syndrome to prior concussion has also become more obvious. The postconcussion syndrome was clarified as a genuine and not infrequent entity, with definitive intracellular and neuropsychological correlations. More recently, a relationship between the cumulative effects of multiple concussion injuries and such conditions as the "punch-drunk" syndrome (dementia pugilistica) or an increased likelihood of Alzheimer disease has become apparent. ${ }^{17}$

The JAMA article and his subsequent work established neurosurgeons as part of the athletic enterprise, and Richard Schneider as the father of sports neurosurgery. For many years he served in this role alone, but his work spawned another generation of neurosurgeons who would greatly expand his legacy. As the data regarding minor head injuries began to surface, another generation of neurosurgeons came forward and began to get involved, particularly in codifying the return-to-play decisions as they relate to nervous system injury.

\section{Robert C. Cantu}

Dr. Cantu attended undergraduate school at the University of California Berkeley campus, during which time he played varsity baseball. He later did his neurosurgical residency at the Massachusetts General Hospital, in the department then chaired by Dr. William Sweet. After a brief stay as a junior faculty member on the Massachusetts General Hospital staff, he entered private practice in Concord, Massachusetts, in the early 1970s, where he continues to practice to this day.

His interest in athletics led him to become team physician for a local high school; he began to investigate the incidence and consequences of minor head injuries, and ultimately expanded his involvement into virtually all sportsrelated organizations in the US. In 1983, he became the first chair of the AANS Section on Sports Medicine. In 1986, he published his concussion grading system and return-to-play guidelines in the journal Physician and Sports Medicine (Table 2). ${ }^{6} \mathrm{He}$ is the medical director for the National Football Head and Neck Injury Register and the National Center for Catastrophic Sport Injury Research, and is a consultant to the NFL, the National Hockey League, and the NCAA. In 2003, he cofounded the Neurological Sports Injury Center at the Brigham and Women's Hospital in Boston, and serves as its codirector. That same year, he was named a principal editor (sports) for the CNS journal Neurosurgery. He has published more than 200 articles, book chapters, and books on the subject of neurological sports injuries, and his persistence and contributions in the area of concussions has had a dramatic effect on the way minor head injury is managed at all levels of athletics throughout the world.

\section{Joseph C. Maroon}

Whereas Dr. Cantu initiated our standardization of this common athletic injury, Joseph Maroon aided in furthering these developments by linking concussion to neuropsychological testing. Maroon was a tailback at the 


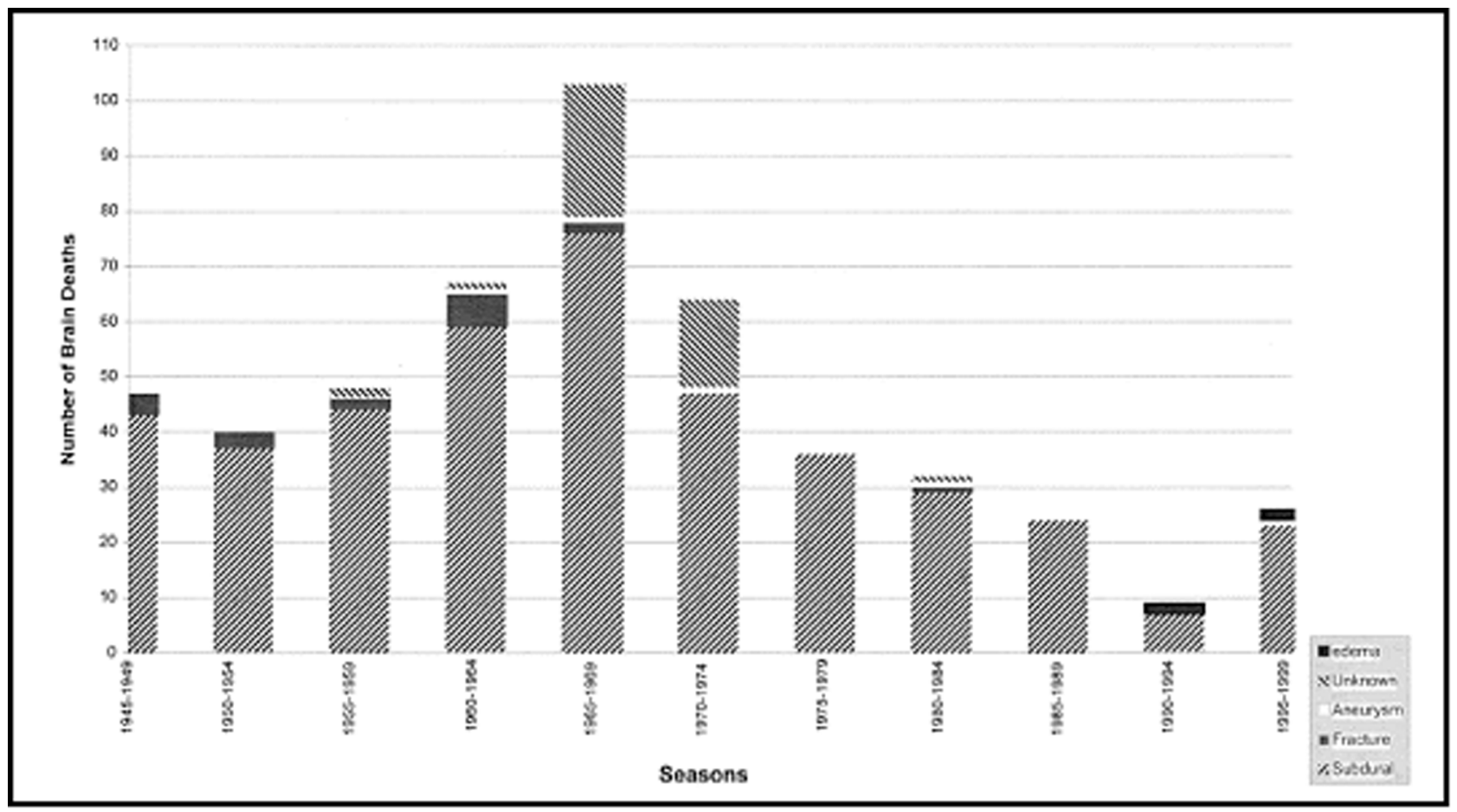

FIG. 3. Bar graph showing data from the National Football Head and Neck Injury Register and the National Center for Catastrophic Sport Injury Research, which were created to monitor the incidence and severity of these types of injuries. Note the decline in brain death injuries after 1969 and the second, smaller rise in 1995. Reprinted with permission from Cantu RC, Mueller FO: Brain injury-related fatalities in American football, 1945-1999. Neurosurgery 52: $846-853,2003$.

University of Indiana and did his residency there before joining the University of Pittsburgh faculty in 1972. Like Cantu, he became involved soon thereafter as an advisor to local sports teams. In 1976 he documented the "burning hands syndrome," which was a warning sign for potential central spinal cord injury ${ }^{14}$ his continued local involvement led to his affiliation with the Pittsburgh Steelers as that team's neurosurgeon. He was the second chair of the AANS Section on Sports Medicine, and in 1985 he served as the president of the CNS.

In 1990, he began an intensive investigation into the neuropsychological consequences of concussion in football. He was challenged by legendary Steelers coach Chuck Noll, who wanted objective data regarding when his players could return to play. In combination with Drs. Mark Lovell and Mickey Collins, he developed a standardized approach to testing athletes with concussion called ImPACT, ${ }^{15,16}$ which consisted of a software package used to assess baseline and postconcussive performance in a battery of simple tests. The test provided correlation between concussion and recovery based on objective test performance, and gave hard data to chronicle concussion and postconcussive syndromes. How long is the "concussed" athlete impaired on objective measures, and how does this compare to postconcussive symptoms? Standard ImPACT performance on processing speed suggests that performance returns to baseline at approximately 7 days postinjury; these findings correlate with laboratory results in which reduction in cerebral blood flow and calcium abnormalities do not recover for approximately 7 days. ${ }^{15,16}$

As a result, we now have a much more sophisticated sense of when an athlete may return to play-the athlete must be free of symptoms and able to complete game-like physical exercise, which correlates with normalization of neuropsychological performance. The ImPACT and similar computerized neuropsychological testing methods are now used by the majority of NFL teams as well as scores of other professional, college, and high school programs around the country. The importance of this work was underscored recently in a case in which the cadaver of a former NFL player who had displayed signs of chronic traumatic encephalopathy showed amyloid plaques and neurofibrillary tangles at autopsy, highlighting the outcomes of inappropriately managed repetitive head injury. ${ }^{17}$

\section{Julian E. Bailes}

Dr. Bailes has also played a significant part in neuro-

TABLE 2

Summary of the Cantu concussion grading system

\begin{tabular}{cc}
\hline \hline Grade & \multicolumn{1}{c}{ Characteristics } \\
\hline 1 (mild) & $\begin{array}{r}\text { no loss of consciousness; posttraumatic amnesia* or postcon- } \\
\text { cussion signs or symptoms lasting less than } 30 \text { minutes } \\
\text { loss of consciousness lasting less than } 1 \text { minute; postraumatic } \\
\text { amnesia* or postconcussion signs or symptoms lasting } \\
\text { longer than 30 minutes but less than } 24 \text { hours }\end{array}$ \\
3 (severe) & $\begin{array}{c}\text { loss of consciousness lasting more than than } 1 \text { minute or post- } \\
\text { traumatic amnesia* lasting longer than } 24 \text { hours; postcon- } \\
\text { cussion signs or symptoms lasting longer than } 7 \text { days }\end{array}$ \\
\hline
\end{tabular}

* retrograde and anterograde. 
surgeons' contributions to sports. He was a Louisiana high school All-State and All-Star football player, and played for Northwestern State at the collegiate level. After graduating from Louisiana State University and Louisiana State University School of Medicine in New Orleans, he went on to train in neurosurgery under Anthony Raimondi at Northwestern University before completing a cerebrovascular/skull base fellowship at the Barrow Neurological Institute. He became the fourth chair of the AANS Section on Sports Medicine in 1989. He has coedited a book titled Neurological Sports Medicine: A Guide for Physicians and Trainers, ${ }^{2}$ and he has been the chief of neurosurgery at West Virginia University since 2000.

Early in his career, he made significant contributions regarding the safe return-to-play guidelines in athletes with spinal cord injury. ${ }^{3}$ Just as Dr. Schneider noted a burgeoning morbidity rate in football, which would later lead to banning of spearing and a subsequent reduction in related injuries, Dr. Bailes noted a spike in deaths that occurred in the last 5 years of the twentieth century. At the same time, there was a cluster of heatstroke deaths in athletes, all of whom died in training-related incidents with core temperatures in excess of $106^{\circ} \mathrm{F}$. Investigation of this cluster of deaths led to delineation of the risks of heatstroke to the athlete, which led to a publication in Neurosurgery that made a dramatic impact on the training regimens of sports teams in the summer months. It also led to the recognition that ephedrine use may have been a contributing factor in these deaths. ${ }^{1}$

\section{Continuing Progress}

With regard to brain injury, it is clear that we have seen a substantial change in the way certain sports are played and trained for, based on the observations made by these individuals. Our specialty has also made significant progress in our approach to athletes with injuries to the spinal column, but these advances have not followed the same dramatic course as in the history of reducing brain injury.
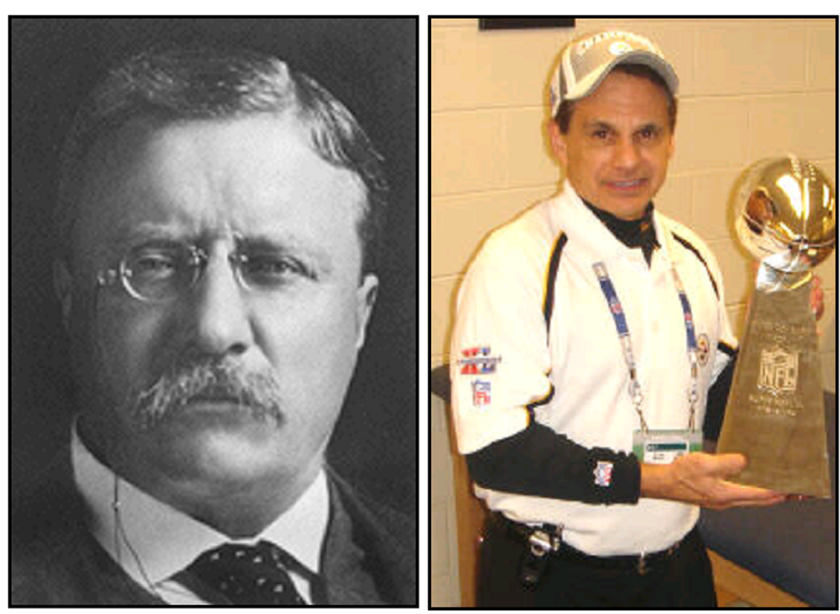

.IG. 4. Photographs marking 100 years of progress: Theodore Roosevelt (circa 1906), who threatened to ban football because of the high rate of fatalities, and Joe Maroon (2006), who standardized return-to-play decisions with his ImPACT test and is shown here with the Vince Lombardi trophy after the Pittsburgh Steelers victory in Super Bowl XL.
Although much remains to be done in the restoration of functioning in athletes with spinal cord injuries, neurosurgery has promoted techniques that allow the expeditious return to play in athletes with herniated disc disease. Twenty years ago, a starting quarterback at a major college program ruptured his L4-5 disc while playing basketball, with persistent L-5 radiculopathy despite conservative treatment. A percutaneous discectomy completely relieved his pain; he recovered well, and started his first game 4 weeks later, throwing for more than 400 yards. An All-American point guard who ruptured his L4-5 disc just before the conference tournament began underwent a minimally invasive discectomy. He scored 14 points in a game 20 days later and led his team to victory against a conference rival. Both of these cases gained national attention, both on television and in the press, and provided great exposure for what our specialty can do for elite athletes to allow them to return to competition.

\section{Conclusions}

Richard Schneider has indeed left a great legacy. Until the mid-to-late twentieth century, he was the only neurosurgeon who carried forward this niche of our specialty. A number of neurosurgeons have taken up his baton, not the least of whom is Michael Apuzzo, who has taken on a championing role in the publication of athletics-related articles in the CNS journal Neurosurgery. It has been 100 years since Teddy Roosevelt said it was too dangerous to play football. Never could there be a more pertinent reminder of how far neurosurgery and its contributions have come since that time than the image of Joe Maroon holding the Vince Lombardi trophy after the Pittsburgh Steelers won the Super Bowl in 2006 (Fig. 4). He was integral to the team as their physician, and his work with ImPACT has made him integral to all sports.

Richard Schneider, Bob Cantu, Joe Maroon, Julian Bailes, and others have made major contributions to the sports arena to maximize the safe practice of intense competition. Their work reminds us that neurosurgeons can and do indeed make a difference. The words of one of the finest leaders of athletes in the past century, Vince Lombardi, ${ }^{13}$ echo as much in our professional training as they do on the field of play.

And in truth, I've never known a man worth his salt who in the long run, deep down in his heart didn't appreciate the grind, the discipline. There is something in good men that really yearns for discipline and the harsh reality of head to head combat. I don't say these things because I believe in the 'brute' nature of man or that men must be brutalized to be combative. I believe in God, and I believe in human decency. But I firmly believe that any man's finest hour-his greatest fulfillment to all he holds dear-is that moment when he has to work his heart out in a good cause and he's exhausted on the field of battle-victorious.

\section{Acknowledgments}

We thank Drs. Julian Hoff and John McGillicuddy for materials used in the Schneider lecture.

\section{References}

1. Bailes JE, Cantu RC, Day AL: The neurosurgeon in sport: awareness of the risks of heatstroke and dietary supplements. Neuro- 
surgery 51:283-288, 2002

2. Bailes JE, Day AL (eds): Neurological Sports Medicine: A Guide for Physicians and Athletic Trainers. Chicago: American Association of Neurosurgeons Press, 2001

3. Bailes JE, Hadley MN, Quigley MR, Sonntag VK, Cerullo LJ: Management of athletic injuries of the cervical spine and spinal cord. Neurosurgery 29:491-497, 1991

4. Bernstein M: Football: The Ivy League Origins of an American Obsession. Philadelphia: University of Pennsylvania Press, 2001

5. BrainyMedia: http://www.brainyquote.com/quotes/authors/ d/dick_butkus.html [accessed 7 September, 2006]

6. Cantu RC: Guidelines for return to contact sports after a cerebral concussion. Physician Sportsmed 14:75-83, 1986

7. Cantu RC, Mueller FO: Brain injury-related fatalities in American football, 1945-1999. Neurosurgery 52:846-853, 2003

8. Cantu RC, Mueller FO: Catastrophic spine injuries in American football, 1977-2001. Neurosurgery 53:358-363, 2003

9. Casale Media: http://www.notable-quotes.com/j/jackson bo.html [accessed 7 September, 2006]

10. Kahn E, Bassett RC, Schneider RC, Crosby E (eds): Correlative Neurosurgery. Springfield, Ill: Charles C Thomas, 1955

11. Kline DG: The making of an academic neurosurgeon: Richard C. Schneider. Surg Neurol 32:255-257, 1989

12. Levy ML, Ozgur BM, Berry C, Aryan HE, Apuzzo ML: Analysis and evolution of head injury in football. Neurosurgery
55:649-655, 2004

13. Lombardi V Jr: What It Takes to be \#1: Vince Lombardi on Leadership. New York: McGraw-Hill, 2001

14. Maroon JC: 'Burning hands' in football spinal cord injuries. JAMA 238:2049-2051, 1977

15. Maroon JC, Lovell MR, Norwig J, Podell K, Powell JW, Hartl $\mathrm{R}$ : Cerebral concussion in athletes: evaluation and neuropsychological testing. Neurosurgery 47:659-672, 2000

16. McClincy MP, Lovell MR, Pardini J, Collins MW, Spore MK: Recovery from sports concussion in high school and collegiate athletes. Brain Inj 20:33-39, 2006

17. Omalu BI, DeKosky ST, Minster RL, Kamboh MI, Hamilton RL, Wecht CH: Chronic traumatic encephalopathy in a National Football League player. Neurosurgery 57:128-134, 2005

18. Schneider RC, Cherry G, Pantek HZ: The syndrome of acute central cervical spinal cord injury; with special reference to the mechanisms involved in hyperextension injuries of cervical spine. J Neurosurg 11:546-577, 1954

19. Schneider RC, Reifel E, Crisler HO, Oosterbaan BG: Serious and fatal football injuries involving the head and spinal cord. JAMA 177:362-367, 1961

Manuscript received August 21, 2006.

Accepted in final form September 7, 2006.

Address reprint requests to: Arthur L. Day, M.D., Department of Neurosurgery, Brigham and Women's Hospital, 75 Francis Street, 
Title

Boston, Massachusetts 02115. email: aday1@partners.org. 